\title{
ВMJ Global Health Square peg in a round hole: re-thinking our approach to evaluating health system strengthening in low-income and middle-income countries
}

\author{
Josephine Borghi, ${ }^{1}$ Zaid Chalabi ${ }^{2}$
}

To cite: Borghi J, Chalabi Z. Square peg in a round hole: re-thinking our approach to evaluating health system strengthening in lowincome and middle-income countries. BMJ Glob Health 2017;2:e000406. doi:10.1136/ bmjgh-2017-000406

Received 15 May 2017 Revised 19 July 2017 Accepted 21 July 2017

\section{CrossMark}

${ }^{1}$ Department of Global Health and Development, London School of Hygiene \& Tropical Medicine, London, UK ${ }^{2}$ Department of Social and Environmental Health Research, London School of Hygiene \& Tropical Medicine, London, UK

Correspondence to Dr Josephine Borghi; jo.borghi@|shtm.ac.uk
To function effectively, health systems require adequate financing; an effective workforce; reliable information for decision making; good governance; and available medicines and health technologies to deliver quality services to their populations. ${ }^{1}$ In low-income and middle-income countries (LMICs), health systems are often limited in this respect and fail to provide comprehensive population coverage of quality healthcare interventions. Health system strengthening comprises strategies to improve one or more of the functions of the health system in order to improve access, coverage, quality or efficiency, ${ }^{1}$ and is recognised to be an essential step towards achieving universal coverage goals. ${ }^{2}$ Only when health systems function efficiently and effectively can they deliver services to meet population needs. The health system is recognised to be a complex and adaptive web of relationships and interactions between people, institutions and resources, and the need for a complex adaptive systems approach to their evaluation has been recognised by researchers and policy makers. ${ }^{34}$ While the application of systems thinking to LMIC health systems is growing, this remains largely descriptive and qualitative in nature. ${ }^{5}$ In this paper, we begin by describing the growing importance of donor attention to health systems and resulting aid flows. We argue that current research methods are inadequate to accurately address donor needs: to demonstrate value for money for health systems relative to disease control programmes in a way that recognises and reflects the complexity of the health system and avoids reductionism; and to test system strengthening strategies in the lab, to understand how they work and potential adverse events so as to optimise design. We argue that complexity science methods, and in particular

\section{Summary box}

Health system strengthening is an essential step towards achieving universal coverage goals in low-income and middle-income countries (LMICs). However, health systems are complex and health system strengthening initiatives are often introduced with limited understanding of how they will work in practice and the risk of potential adverse events

- Aid flows to health systems in LMICs have increased substantially in the last 15 years. Donors want to know whether their investments in health system strengthening represent value for money relative to disease control programmes and how to optimise the design of such programmes.

- Conventional evaluation methods ignore the complex dynamic nature of health systems and are insufficient to serve donor needs.

- System dynamics and agent-based modelling methods can reflect the complexity of health systems and be used to estimate value for money for health systems investments in LMICs and predict health system response to any stimulus prior to its introduction, including the detection of potential adverse events.

- There has been very limited application of system dynamics and agent-based modelling within the evaluation of health system strengthening initiatives in LMICs, and their future use by researchers is highly recommended.

system dynamics modelling (SDM) and agentbased modelling (ABM), offer a promising means of effectively operationalising systems thinking to assess and maximise value for money for health systems programmes in LMICs.

In recognition of their importance, aid flows to health systems have been growing. Development assistance to health systems increased from US\$ 540 million in 1990 to 2.7 billion in $2015 .{ }^{6}$ Global health initiatives opened up funding streams to support health system strengthening in eligible countries 
in the mid-2000s. In Global Fund Round 8 grants, for example, almost $40 \%$ of funds went to health system strengthening $^{7}$, and around $10 \%$ of the Global Alliance for Vaccines and Immunisation funds between 2006 and $2013 .^{8}$ These figures do not reflect the substantial sums that have been allocated by donors to interventions aimed at strengthening specific health system pillars (eg, financing, human resources). For example, results-based financing programmes, consisting of financial incentives for health workers, are operating in more than 30 LMICs, supported by US\$ 1.6 billion in low-interest loans from the World Bank and US\$ 410 million from the Results Innovation Trust Fund.

Increasingly, donor governments want to know whether their investments are paying off, and how much to invest in health systems relative to specific disease control programmes, and the relative impacts on population health or value for money of each. ${ }^{9-11}$ Although important, this question risks pushing researchers away from a systems thinking perspective and towards isolating, quantifying and comparing the population-level effects of strategies aimed at strengthening a particular part of the system (eg, financing vs governance) ${ }^{10}$ Evaluations of health systems investments usually apply conventional methods to demonstrate programme effectiveness by measuring changes in patient and population outcomes (eg, ref 12 13). This is problematic as it treats the health system as static, one-dimensional, one-directional and linear. ${ }^{14}$ By their nature, health systems are, however, dynamic, multidimensional, non-linear and with feedback loops. ${ }^{1516}$ The elements of a health system do not all respond simultaneously to a programme because there are inherent time delays associated with the progression of the programme effects through the system. There is communication between each of the health system elements or 'pillars' and feedback, the relationship is not unidirectional. Nor do elements operate independently of one another, for example, changes in financing arrangements will inevitably affect governance structures and human resources, which can in turn feedback and influence financing. Finally, the response of the health system is in general non-linear because the overall impact of two independent stimuli is not necessarily additive (the sum of the impacts of the two stimuli considered separately), it can be superadditive or subadditive.

Furthermore, the current emphasis and demand for evidence is focused on evaluation of interventions that have been implemented. ${ }^{3}$ Because strengthening the health system is generally perceived as a good, such programmes are often implemented in hospitals and clinics, impacting directly on health workers and patients, with very limited if any insight or understanding of how they will work and the risk of potential adverse events. ${ }^{17}$ Yet for new drugs, pharmacological testing is required to understand the effect of the drug on the human body (pharmacodynamics), and to determine the required dosage, and monitor adverse events/safety, prior to clinical trials. Only once the mechanism of action is understood are efficacy studies carried out. While systems thinking approaches can be used to inform the design of programmes, ${ }^{318}$ typically no formal test of concept is carried out for health systems programmes, partly because their benefit is not questioned, and partly because of the absence of appropriate tools. Yet exploring the potential effects of programmes in the lab and testing responses to potential design changes before implementation would reduce the risk of adverse events in the real world, and further help to optimise design.

There are a variety of complexity science methods that can be used to unpack the complexity of healthcare systems in an LMIC setting, including network analysis, scenario planning and two mathematical modelling methods: SDM and ABM. ${ }^{19}$ Although all these methods can capture the complex static non-linear associations between elements of a complex system, only $\mathrm{SDM}^{20}$ and $\mathrm{ABM}^{2122}$ can model dynamic system behaviour such as that observed within health systems.

$\mathrm{ABM}$ and SDM are well-known methods for modelling complex sociotechnical dynamic systems, including the dynamic behaviour of an accident and emergency department $^{23}{ }^{24}$; accountable care organisations ${ }^{25}$; accountable care organisations ${ }^{25}$; policies to make care more affordable $^{26}$; vaccine distribution systems ${ }^{27}$; and neonatal health policies ${ }^{28}$ among many others (eg, 29). These models can be used to evaluate and quantify ex ante the response of a health system to any stimulus, including potential adverse events, ${ }^{30}$ be it for a new programme, or additional resources, a sudden disease outbreak or a natural disaster. The models would provide a computational experimental framework for optimising the performance of a health system ${ }^{23} 3132$ prior to in vivo testing of pilot programmes, and for enhancing the resilience of a health system to potential exogenous disturbances. Models can also be used to inform the design of subsequent empirical evaluations. System dynamics represents a top-down approach where the interest is in modelling the complex macrobehaviour of the system. ABM on the other hand is a bottom-up approach which is ideally suited to model emergent complex macrobehaviour which can only be deduced from modelling interactions at the microlevel between the different elements of the system (eg, health workers, healthcare managers and patients). Model structure can be informed by detailed descriptive mapping of processes and relationships between variables based on interviews or workshops and using tools such as causal loop diagrams and stock and flow diagrams in the case of system dynamics, or process mapping). ${ }^{33}$ Empirical data are still needed for model calibration where available. Parameter estimates can also be derived through interviews with key stakeholders, from the literature or from data from other settings with appropriate adjustments. It is also important to carry out comprehensive sensitivity analysis (deterministic or probabilistic) to evaluate the sensitivity of the outcomes of interest to the uncertainty in the parameter estimates. Each modelling approach has its advantages and disadvantages, and 
the ideal approach for modelling a health system would depend on the specifics of the system and the nature of the programme under consideration, although the two approaches may also complement each other in understanding complex system behaviour. ${ }^{34}$

To date, there has been surprisingly limited application of these methods within (ex ante or ex post) evaluation of health systems interventions in low-income and middle-income settings. In relation to other classical mathematical modelling methods (eg, statistical models), the use of ABM and SDM poses greater challenges to model validation. ${ }^{35}$ However, there is always a balance to strike between faithfully representing the real world with its complexity by using ABM and SDM and alternatively using simple modelling approaches that oversimplify system behaviour. These methods offer great potential to add new insights into the relative effectiveness of health system strengthening compared with disease control programmes and to optimise design prior to implementation. We highly recommend their future use by researchers in this field.

Contributors JB had the idea for the paper and wrote the first draft. ZC wrote part of the paper and commented on all drafts.

Competing interests None declared.

Provenance and peer review Not commissioned; externally peer reviewed. Data sharing statement Not applicable.

Open Access This is an Open Access article distributed in accordance with the terms of the Creative Commons Attribution (CC BY 4.0) license, which permits others to distribute, remix, adapt and build upon this work, for commercial use, provided the original work is properly cited. See: http://creativecommons.org/ licenses/by/4.0/

(C) Article author(s) (or their employer(s) unless otherwise stated in the text of the article) 2017. All rights reserved. No commercial use is permitted unless otherwise expressly granted.

\section{REFERENCES}

1. World Health Organization. Everybody's business: Strengthening health systems to improve health outcomes. WHO's framework for action. Geneva: World Health Organization, 2007. http://www.who. int/healthsystems/strategy/everybodys_business.pdf.

2. Atun R, de Andrade LO, Almeida G, et al. Health-system reform and universal health coverage in Latin America. Lancet 2015;385:1230-47.

3. Adam T, Hsu J, de Savigny D, et al. Evaluating health systems strengthening interventions in low-income and middle-income countries: are we asking the right questions? Health Policy Plan 2012;27(suppl 4):iv9-19.

4. Alliance for Health Policy and Systems ResearchSystems Thinking for Health Systems Strengthening. Geneva: World Health Organization, 2009.

5. Adam T. Advancing the application of systems thinking in health Health Res Policy Syst 2014;12:50.

6. Dieleman JL, Schneider MT, Haakenstad A, et al. Development assistance for health: past trends, associations, and the future of international financial flows for health. Lancet 2016;387:2536-44.

7. Warren AE, Wyss K, Shakarishvili G, et al. Global health initiative investments and health systems strengthening: a content analysis of global fund investments. Global Health 2013;9:30.

8. Tsai FJ, Lee H, Fan VY, et al. Perspective and investments in health system strengthening of Gavi, the Vaccine Alliance: a content analysis of health system strengthening-specific funding. Int Health 2016;8:246-52.

9. House of Commons International Development Committe. Strengthening Health Systems in developing countries. 5th Report of session 2014-2015. London, UK, 2014. https://publications. parliament.uk/pa/cm201415/cmselect/cmintdev/246/246.pdf.

10. Hatt L, Johns B, Connor C, et al. Impact of Health Systems strengthening on Health. Bethesda, MD : Health Finance \& Governance Project, Abt Associates, 2015.

11. Jackson P. Value for money and international development: deconstructing myths to promote a more constructive discussion. Paris, France: OECD Development Co-operation Directorate, 2012.

12. Dzakpasu S, Powell-Jackson T, Campbell OM, et al. Impact of user fees on maternal health service utilization and related health outcomes: a systematic review. Health Policy Plan 2014;29:137-50.

13. Turcotte-Tremblay AM, Spagnolo J, De Allegri M, et al. Does performance-based financing increase value for money in low- and middle- income countries? A systematic review. Health Econ Rev 2016;6:30.

14. Adam T, de Savigny D. Systems thinking for strengthening health systems in LMICs: need for a paradigm shift. Health Policy Plan 2012;27(Suppl 4):iv1-3.

15. Paina L, Peters DH. Understanding pathways for scaling up health services through the lens of complex adaptive systems. Health Policy Plan 2012;27:365-73.

16. Sterman JD. Learning from evidence in a complex world. Am J Public Health 2006;96:505-14.

17. Atun R. Health systems, systems thinking and innovation. Health Policy Plan 2012;27(suppl 4):iv4-8.

18. Brainard J, Hunter PR. Do complexity-informed health interventions work? A scoping review. Implement Sci 2016;11:127.

19. Peters $\mathrm{DH}$. The application of systems thinking in health: why use systems thinking? Health Res Policy Syst 2014;12:51.

20. Sterman JD. Business dynamics. Systems thinking and modelling of the complex world. Boston: Irwin McGraw Hill, 2000.

21. Epstein JM, science G. Studies in agent-based computational modelling. Princeton: Princeton University Press, 2006.

22. Marshall DA, Burgos-Liz L, IJzerman MJ, et al. Applying dynamic simulation modeling methods in health care delivery research-the SIMULATE checklist: report of the ISPOR simulation modeling emerging good practices task force. Value Health 2015;18:5-16.

23. Lane DC, Monefeldt C, Rosenhead JV, et al. Looking in the wrong place for healthcare improvements: A system dynamics study of an accident and emergency department. $J$ Oper Res Soc 2000;51:518-31.

24. Kanagarajah AK, Lindsay P, Miller A, et al. An exploration into the uses of Agent-Based modeling to improve Quality of Health Care Unifying Themes in Complex Systems. Berlin Heidelberg: SpringerVerlag, 2010:471.

25. Liu P, Wu S. An agent-based simulation model to study accountable care organizations. Health Care Manag Sci 2016;19:89-101.

26. Milstein B, Homer J, Hirsch G, et al. Analyzing national health reform strategies with a dynamic simulation model. Am J Public Health 2010;100:811-9.

27. Lee BY, Mueller LE, Tilchin CG, et al. A systems approach to vaccine decision making. Vaccine 2017;35(suppl 1):A36-42.

28. Semwanga AR, Nakubulwa S, Adam T, et al. Applying a system dynamics modelling approach to explore policy options for improving neonatal health in Uganda. Health Res Policy Syst 2016;14:35.

29. Homer J, Milstein B, Hirsch GB, et al. Combined Regiona Investments Could Substantially Enhance Health System Performance And Be Financially Affordable. Health Aff 2016;35:1435-43.

30. Davies TP, Fry HM, Wilson AG, et al. A mathematical model of the London riots and their policing. Sci Rep 2013;3:1303.

31. Lane DC, Husemann E. System dynamics mapping of acute patient flows. Journal of the Operational Research Society 2008;59:213-24.

32. Macmillan A, Davies M, Shrubsole C, et al. Integrated decisionmaking about housing, energy and wellbeing: a qualitative system dynamics model. Environ Health 2016;15(suppl 1):37.

33. Lane DC, Munro E, Husemann E, et al. Blending systems thinking approaches for organisational analysis: reviewing child protection in England. Eur J Oper Res 2016;251:613-23.

34. Scholl HJ. Agent-based and system dynamics modelling: a call for cross study and joint research. Proceedings of the 34th Annual Hawi International Conference on System Sciences (HICSS-34), 2001.

35. Barlas Y. Formal aspects of model validity and validation in system dynamics. Syst Dyn Rev 1996;12:183-210.

36. Windrum P, Fagiolo G, Moneta A, et al. Empirical validation of agentbased models: alternatives and prospects. J Artif Soc Soc Simulat 2007;10:8. 